\title{
Infantile Onset Spinocerebellar Ataxia Represents an Allelic Disease Distinct from Other Hereditary Ataxias
}

\author{
KAISU NIKALI, TUULA KOSKINEN, ANU SUOMALAINEN, HELENA PIHKO, \\ AND LEENA PELTONEN \\ Laboratory of Human Molecular Genetics, National Public Health Institute, FIN-00300 Helsinki, \\ Finland [K.N., A.S., L.P.], and Department of Child Neurology, Children's Hospital, University \\ of Helsinki, FIN-00290 Helsinki, Finland [T.K., H.P.]
}

\section{ABSTRACT}

\begin{abstract}
Hereditary ataxias are a heterogeneous group of progressive neurodegenerative disorders characterized by symptoms and signs originating mainly in the CNS. A new representative of this disease group is infantile onset spinocerebellar ataxia, an autosomal recessively inherited syndrome so far reported only in the genetically isolated Finnish population. The etiology of hereditary ataxias still remains unknown, but the gene loci behind many of them have been mapped to different chromosomal regions. We have carried out linkage analyses with markers on the regions of the previously identified ataxia loci to determine whether the infantile onset spinocerebellar ataxia syndrome represents the same allelic disease as any of the previously identified hereditary ataxias. Here we report that the infantile onset spinocerebellar ataxia syndrome
\end{abstract}

does not segregate with any of the markers closely linked to the other hereditary ataxias. Consequently, it represents a genetically distinct disease, the gene locus of which still has to be identified. (Pediatr Res 36: 607-612, 1994)

\section{Abbreviations}

IOSCA, infantile onset spinocerebellar ataxia

FA, Friedreich's ataxia

AVED, ataxia with selective vitamin E deficiency

AT, ataxia telangiectasia

SCA1, spinal cerebellar ataxia 1

SCA2, spinal cerebellar ataxia 2

cM, centimorgan

FSP, familial spastic paraplegia

PCR, polymerase chain reaction
Hereditary ataxias are a heterogenous group of progressive neurodegenerative disorders characterized by cerebellar symptoms, combined with features including peripheral neuropathy, ophthalmoplegia, optic atrophy, retinal degeneration, deafness, endocrinologic symptoms, and cardiomyopathy. Some of the diseases, e.g. FA, are clinically and genetically well defined, but the etiology of the majority of them is unknown. Classification of the different syndromes is based on the clinical symptoms, the age of onset, and the pattern of inheritance (1).

We have recently described a new form of hereditary ataxia, IOSCA $(2,3)$. The clinical symptoms in this syndrome include cerebellar ataxia associated with peripheral sensory neuropathy, cerebral symptoms including athetosis and epilepsy, deafness, ophthalmoplegia, optic atrophy, and, in females, primary hypogonadism. We have identified 19 patients with this recessively in-

Received February 14, 1994; accepted May 24, 1994.

Correspondence and reprint requests: Kaisu Nikali, Department of Human Molecular Genetics, National Public Health Institute, Mannerheimintie 166, FIN00300 Helsinki, Finland. herited disease in the genetically isolated population of Finland.

Most ataxia syndromes are hereditary, and both autosomal dominant and autosomal recessive inheritance have been reported. Because the basic biochemical abnormality is unknown in these diseases, a random search of the human genome would be a relevant approach to revealing the defective gene loci. The random mapping procedure uses highly polymorphic and multiallelic DNA markers that have been assigned to certain chromosomal regions. The data of the inheritance of the disease in the families is compared with the inheritance pattern of the marker alleles in the same families. The probabilities for the disease and the marker loci being closely located, i.e. linked, are calculated using the LINKAGE package of computer programs (Jurg Ott, Columbia University, New York). Indeed, the loci for several hereditary ataxias have been successfully assigned by means of random linkage analyses.

The gene for recessively inherited FA, which is the most frequent of all hereditary ataxias, has been mapped 
to the long arm (q) of chromosome 9 (4-6). The gene locus of a similar kind of ataxia resulting from selective vitamin E deficiency (AVED) has been localized to the proximal part of chromosome 8q (7). AT is an autosomal recessive disease manifesting itself in childhood, and the corresponding gene maps to the chromosomal region 11q22-q23 (8). Autosomal dominant SCA1 and SCA2 are also assigned to different genetic loci: the genes for SCA1 and SCA2 have been mapped to chromosomal regions 6 p23-p24 $(9,10)$ and 12q23-q24.1 (11), respectively. In addition, some types of FSP bear a close resemblance to the hereditary ataxias. Autosomal dominant FSP has been shown to be genetically heterogenous, but one locus has been mapped to chromosome $14 \mathrm{q}(12)$.

The aim of this study was to determine whether the Finnish form of hereditary ataxia, IOSCA, represents the same allelic disease as any of the previously known hereditary ataxias. We used IOSCA family material to perform linkage analyses to the microsatellite markers flanking the known ataxia loci.

\section{METHODS}

All the 13 known Finnish IOSCA families, with 42 healthy and 19 affected family members, were included in this study. Informed consent was obtained from all the families. Six families had two affected children, the rest only one affected child. The patients were diagnosed at the Children's Hospital of the University of Helsinki. The diagnosis was based on the following clinical symptoms: acute or subacute appearance of ataxia, athetosis, and the loss of deep tendon reflexes in a child with normal development until the age of 9 to $18 \mathrm{mo}$ as well as deafness, ophthalmoplegia, optic atrophy, and sensory neuropathy, which subsequently developed during childhood years $(2,3)$.

DNA analysis. Ten $\mathrm{mL}$ of peripheral venous blood was obtained from all the individuals, and genomic DNA was extracted from the leukocytes by standard procedures (13). A total of 28 highly polymorphic amplifiable microsatellite markers were analyzed. The PCR (14) primers used to amplify the marker sequences originated either from the Genethon (Eury, France) amplifiable marker collection (The Genethon Microsatellite Map Catalogue, 1992) or the marker collection of the Nordic Human Genome Organization collaboration project. The order of the markers and the genetic distances between them were based on published genetic maps (15-17). One of the primers was $5^{\prime}$ end-labeled with ${ }^{32} \mathrm{P}-\gamma \mathrm{ATP}$ (Amersham, Little Chalfont, UK) using T4-polynucleotidekinase (Pharmacia, Piscataway, NJ) in its buffer at $37^{\circ} \mathrm{C}$ for 30 min. PCR was performed in a volume of $15 \mu \mathrm{L}$ containing $12 \mathrm{ng}$ of template DNA, 3 pmol of primers, $0.2 \mu \mathrm{M}$ each of the nucleotides, $20 \mathrm{mM}$ Tris- $\mathrm{HCl}(\mathrm{pH} 8.8), 15 \mathrm{mM}$ $\left(\mathrm{NH}_{4}\right)_{2} \mathrm{SO}_{4}, 1.5 \mathrm{mM} \mathrm{MgCl} 2,0.1 \%$ Tween $20,0.01 \%$ gelatin, and $0.25 \mathrm{U}$ Thermus aquaticus DNA polymerase (Promega, Madison, WI). The PCR conditions in multiwell microtitration plates were as follows: denaturation at $92^{\circ} \mathrm{C}$ for $30 \mathrm{~s}$, annealing at $48-64^{\circ} \mathrm{C}$ (depending on primers) for $30 \mathrm{~s}$, and extension at $72^{\circ} \mathrm{C}$ for $30 \mathrm{~s}$ for 28 cycles. In the first cycle, however, denaturation lasted for $3 \mathrm{~min}$, and extension in the last cycle was $5 \mathrm{~min}$. The amplified fragments were separated by electrophoresis $(1400 \mathrm{~V}, 4$ h) in 5\% denaturing polyacrylamide sequencing gels. The gels were dried and subjected to autoradiography on Kodak X-omat film for $2-48 \mathrm{~h}$. The different alleles of the polymorphic markers were determined from the autoradiographs.

Computer analysis. To find out whether any conclusive results could be drawn from linkage analysis of the available family material, we first carried out data simulation analysis assuming a single marker locus and double heterozygosity in the parents. We used the MSIM option of the SLINK program with 500 replicates (one replicate equals one round of generating marker genotype for each individual) to obtain the elod (expected logarithm of the odds score) values $(18,19)$.

We compared the inheritance pattern of the different alleles of the polymorphic markers with the inheritance of the disease in the families. To calculate the likelihood, expressed as a pairwise lod score, of the possibility that the disease and the marker loci are located close to each other, we used the MLINK option of the LINKAGE package programs (version 5.10), assuming an autosomal recessive pattern of inheritance for the IOSCA gene with an estimated frequency of $10^{-3}$ in the Finnish population and equal recombination rates for the males and females (20). Because of the early onset of the disease, complete penetrance was assigned. The disease is enriched in the genetically isolated Finnish population; the possibility of locus heterogeneity can be considered highly unlikely and locus homogeneity was assumed. The allele frequencies for each marker were assumed to be equal, because DNA samples were available from most subjects. Multipoint analyses combining the information from the markers on the same chromosomal region were carried out with the LINKMAP program of the LINKAGE package.

\section{RESULTS}

We analyzed markers on the six different chromosomal regions flanking the gene loci reported to be associated with hereditary ataxias in all 13 Finnish IOSCA families identified and diagnosed in this population (Fig. 1). The family material included only six families with two affected children, the rest of them having only one diseased child. Consanguinity was identified in two of the families; the parents of one family were first cousins, and the father of one patient was a second cousin of another patient. Fourteen of the 19 patients originated from North Carelia, a county in the eastern part of Finland (Fig. 2). Although the majority of the ancestors originated from eastern Finland, many of their birthplaces are scattered throughout the country. This suggests that the IOSCA mutation is quite old. However, the clustering of the 

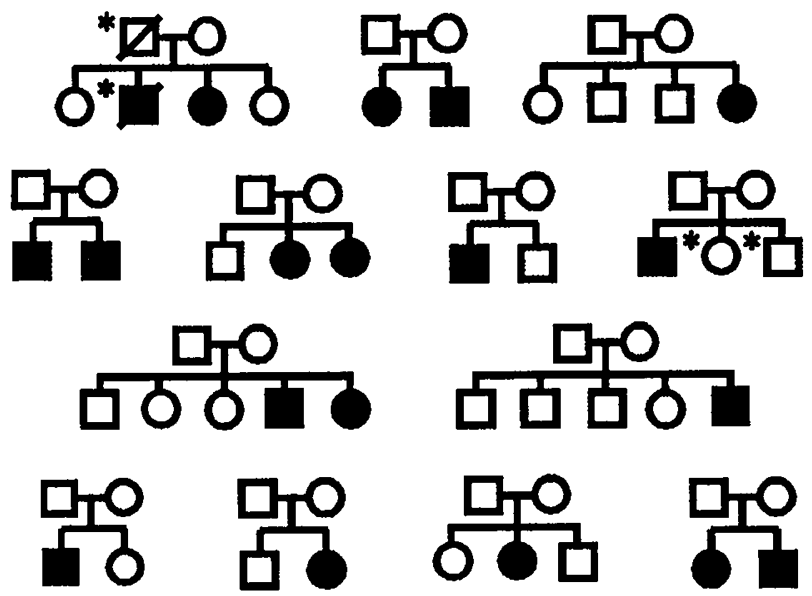

Figure 1. The Finnish families with IOSCA, showing the autosomal recessive pattern of inheritance. Square $=$ male; circle $=$ female; white $=$ healthy; black $=$ affected; ${ }^{*}=$ no sample available.

ancestors in eastern Finland suggests that there is one major mutation behind the syndrome in this population.

Simulation analyses assuming full penetrance and locus homogeneity in this family material revealed a mean elod of 2.979 with a standard deviation of 1.036. The maximum lod score was 4.820 , and at a recombination fraction of 0.01 the expected lod scores ranged from 1.943 to 4.014 (90\% confidence interval). The lod score still remained significant in more than $30 \%$ of the replicates at

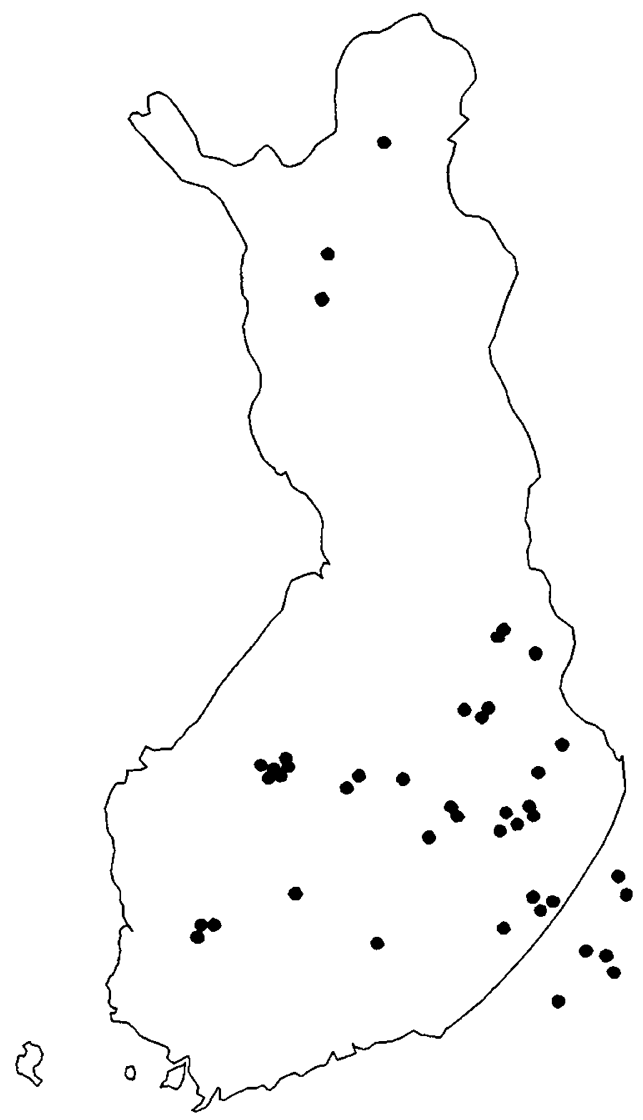

Figure 2. The birthplaces of the grandparents of the IOSCA patients shown on the map of Finland. a recombination fraction of 0.05 . According to this simulation analysis, an evenly spread set of informative markers should result in a conclusive lod score in our limited family material.

Table 1 summarizes the two-point lod scores between the IOSCA syndrome and the markers linked to the loci of the other hereditary ataxias. None of the markers analyzed showed evidence of linkage with the IOSCA gene. The degree of exclusion produced by the different markers varied according to the informativeness of the markers within the families.

The FA gene has been assigned to chromosome 9q13-q21, and strong evidence for linkage was found with marker D9S15 (4-6). By analyzing six polymorphic markers, D9S43, D9S15, D9S175, D9S152, D9S197, and D9S176, we were able to exclude a continuous area of more than $60 \mathrm{cM}$ flanking the FA locus on chromosome 9. In multipoint linkage analyses, the lod scores remained highly negative $(<-3)$ throughout the area spanning from D9S43 to D9S176. This excluded the possibility that the chromosomal region containing the FA gene might also cover the IOSCA gene.

The gene for the AVED syndrome maps to chromosome 8q21 (7) and is tightly linked to the D8S260 marker. Multipoint linkage analyses combining the information from markers D8S285, D8S260, and D8S279 also resulted in negative lod scores and demonstrated that the IOSCA

Table 1. Pairwise linkage data between IOSCA and markers flanking identified ataxia loci

\begin{tabular}{llrrrr}
\hline & & \multicolumn{4}{c}{ Recombination fraction } \\
\cline { 3 - 6 } Marker & Disease & 0.00 & 0.05 & 0.10 & \multicolumn{1}{c}{0.20} \\
\hline D6S309 & SCA1 & $-\infty$ & -2.17 & -1.01 & -0.22 \\
D6S259 & & $-\infty$ & -1.15 & -0.41 & -0.03 \\
D6S285 & & $-\infty$ & -3.55 & -1.74 & -0.47 \\
TNFB & & $-\infty$ & -1.25 & -0.42 & 0.04 \\
D8S285 & AVED & $-\infty$ & -2.85 & -1.54 & -0.50 \\
D8S260 & & $-\infty$ & -2.72 & -1.25 & -0.23 \\
D8S279 & & $-\infty$ & 0.17 & 0.62 & 0.63 \\
D9S43 & FA & $-\infty$ & -2.07 & -0.99 & -0.25 \\
D9S15 & & $-\infty$ & -2.49 & -1.43 & -0.56 \\
D9S175 & & $-\infty$ & -5.47 & -3.08 & -1.14 \\
D9S152 & & $-\infty$ & -3.75 & -2.07 & -0.77 \\
D9S197 & & $-\infty$ & -3.34 & -1.83 & -0.65 \\
D9S176 & & $-\infty$ & -3.36 & -1.85 & -0.68 \\
D11S35 & AT & $-\infty$ & -4.60 & -2.66 & -1.03 \\
DRD2 & & $-\infty$ & -4.57 & -2.57 & -0.98 \\
CD3D & & $-\infty$ & -1.04 & -0.38 & 0.01 \\
D11S925 & & $-\infty$ & -3.00 & -1.73 & -0.68 \\
D12S82 & SCA2 & $-\infty$ & -2.17 & -1.36 & -0.63 \\
D12S78 & & $-\infty$ & -6.23 & -3.47 & -1.25 \\
D12S86 & & $-\infty$ & -0.29 & 0.21 & 0.35 \\
D12S76 & & $-\infty$ & 0.48 & 0.64 & 0.45 \\
D14S80 & FSP & $-\infty$ & -1.72 & -0.65 & -0.01 \\
D14S75 & & $-\infty$ & 0.44 & 0.60 & 0.44 \\
D14S269 & & $-\infty$ & -1.28 & -0.62 & -0.18 \\
D14S66 & & $-\infty$ & -0.96 & -0.25 & 0.17 \\
D14S63 & & $-\infty$ & -1.40 & -0.43 & 0.09 \\
D14S43 & & $-\infty$ & -2.24 & -1.06 & -0.23 \\
D14S74 & & $-\infty$ & -0.96 & -0.10 & 0.33 \\
\hline & & & & & \\
\hline
\end{tabular}


syndrome does not share the same genetic locus as the AVED syndrome either.

The gene locus of the AT syndrome on the chromosomal region 11q22-q23 (8) could be excluded after analysis of the polymorphic markers D11S35, DRD2, CD3D, and D11S925. The strongly negative lod scores $(<-5)$ obtained in the multipoint map combining the information from these markers on the long arm of chromosome 11 showed that the genetic backgrounds of the IOSCA and AT syndromes are not the same.
In analysis of the gene region for the SCA1 syndrome on chromosome $6 \mathrm{p} 22-\mathrm{p} 23(9,10)$, the results of multipoint linkage analyses with markers D6S309, D6S259, D6S285, and TNFB excluded a contiguous area of more than $20 \mathrm{cM}$ extending on both sides of the SCA1 locus as a site for the IOSCA gene. Analogously, linkage analyses of markers D12S82, D12S78, D12S86, and D12S76 excluded a continuous area of nearly $50 \mathrm{cM}$ on distal $12 \mathrm{q}$ as the IOSCA locus, the exclusion flanking the SCA2 locus on 12q23-q24.1 (11).
Lod Score (Z)
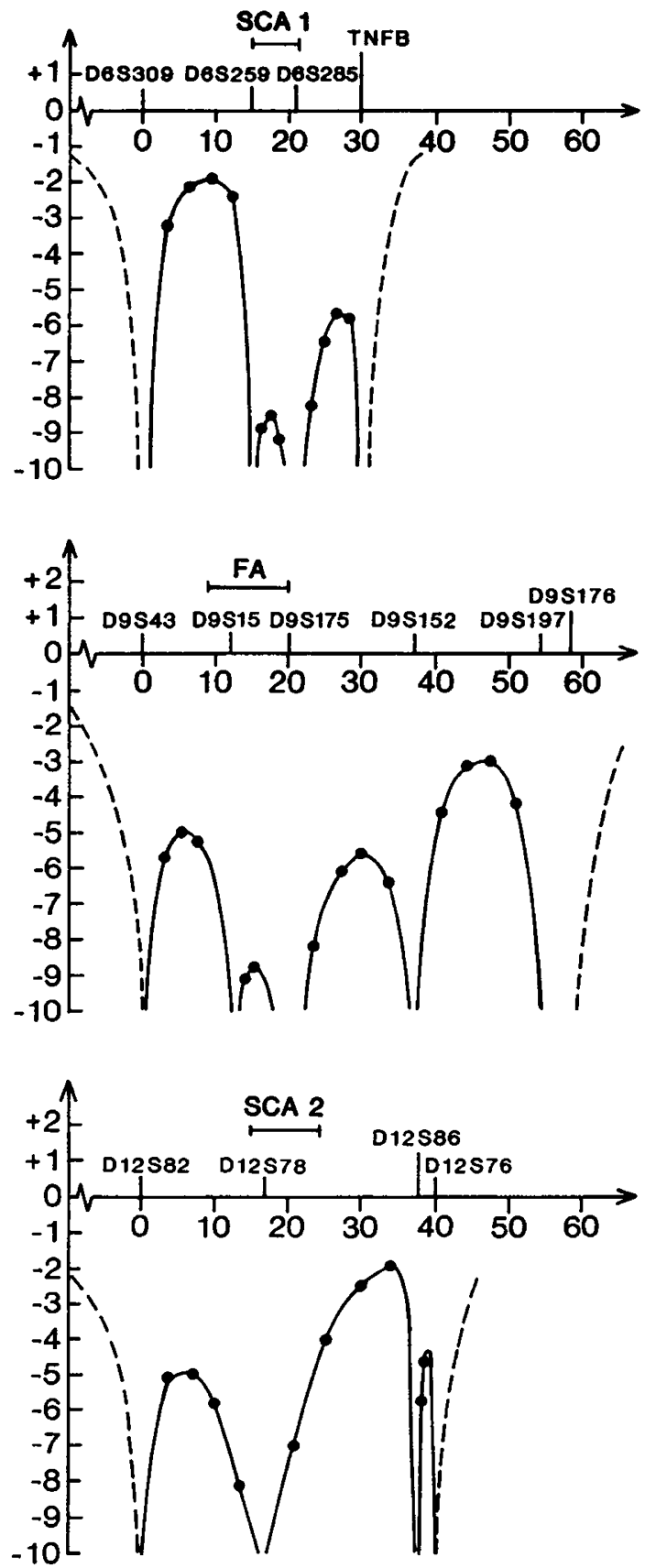

Lod Score (Z)
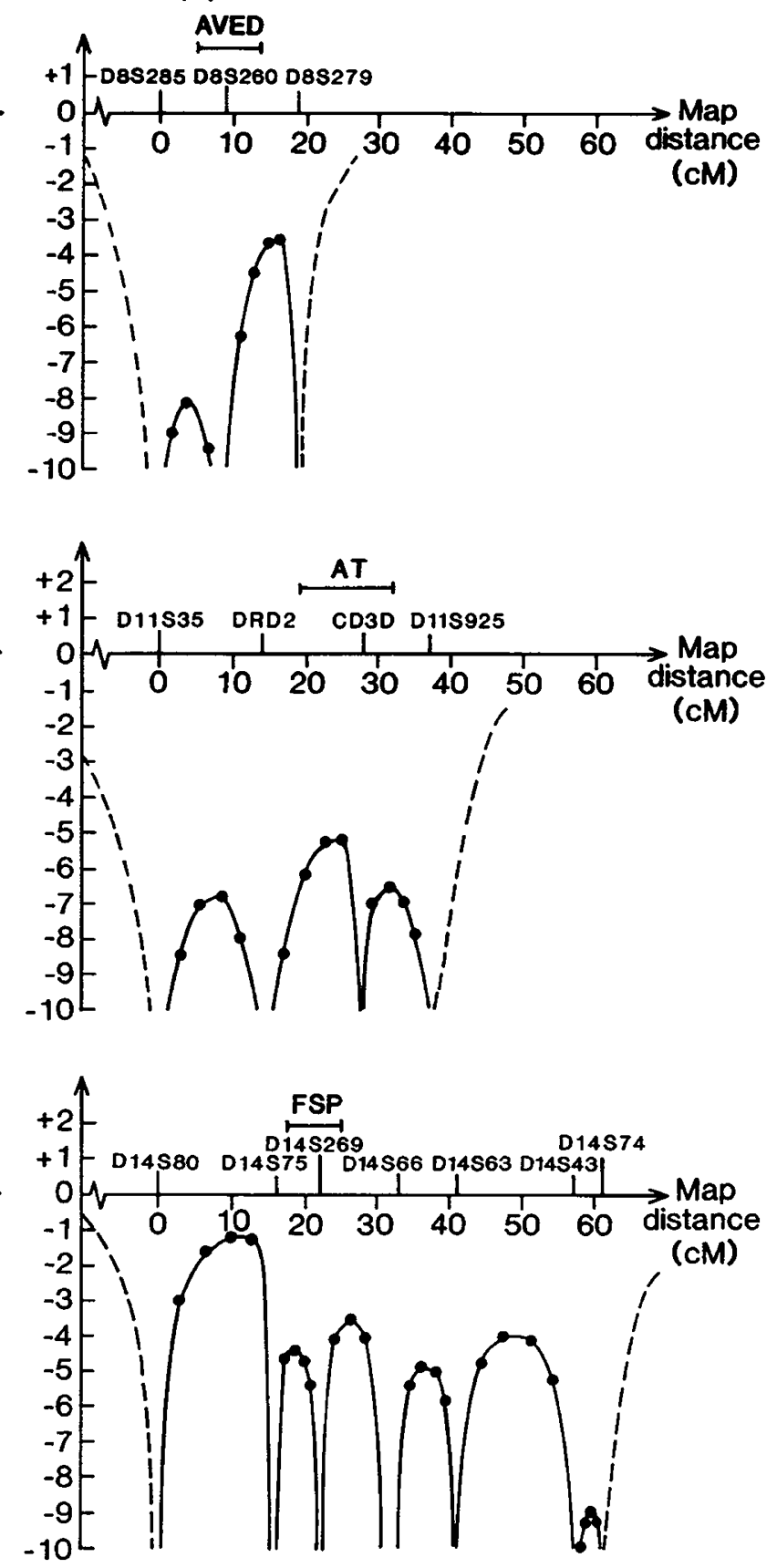

Figure 3. The results of multipoint linkage analyses of the IOSCA syndrome and the previously identified gene loci of hereditary ataxias. The LINKMAP program was used to calculate lod scores for the different locations of the IOSCA gene relative to known fixed positions of the marker loci. The marker codes are shown above the horizontal axis and the distances between the markers are expressed in cM. A gene area was considered excluded if the resulting lod scores with the closely located markers were below -2 . 
Finally, multipoint linkage analysis of markers D14S80, D14S75, D14S269, D14S66, D14S63, D14S43, and D14S74 demonstrated that the IOSCA gene is not located on the region of $70 \mathrm{cM}$ covered by these markers and thus does not represent the same allelic locus as the FSP syndrome type assigned to this chromosomal region (12) (Fig. 3).

\section{DISCUSSION}

The Finnish population has remained genetically isolated throughout the ages for linguistic and geographical reasons. This isolation has led to the enrichment of some 30 hereditary diseases, known as the Finnish disease heritage. Such a genetically isolated population is ideal for genetic research; it creates a unique opportunity to identify the defective gene loci of otherwise rare diseases enriched in this population. In addition, enriched diseases are frequently caused by one ancient mutation, which makes the assignment of disease loci easier, as in the efficient application of linkage disequilibrium in mapping strategies. Indeed, the Finnish population has been successfully used in the mapping of the genes for several severe inherited diseases (21-24).

We have discussed the clinical features of the IOSCA syndrome and compared them with those in other inherited ataxias in detail elsewhere (2). Although the peripheral neuropathy is very similar in the IOSCA and FA syndromes (3), the myocardial damage, typical of the FA syndrome, is not found in the IOSCA patients. The noncerebellar symptoms of the IOSCA syndromeathetosis, ophthalmoplegia, and deafness-are uncommon in the FA syndrome but common in autosomal dominant cerebellar ataxias. Progressive cerebellar atrophy is another common feature of the IOSCA syndrome and most subgroups of the autosomal dominant cerebellar ataxia syndromes, but the mode of inheritance and the age of onset are different. The AVED and AT syndromes do share clinical features with the IOSCA syndrome, but the serum concentrations of vitamin $\mathrm{E}, \alpha$-fetoprotein, and $\operatorname{IgA}$ are normal in IOSCA patients. The loss of deep tendon reflexes and the lack of spasticity differentiate the IOSCA syndrome from the FSP syndrome. At the present time, the 13 IOSCA families reported are all Finnish, making the IOSCA syndrome a typical representative of the Finnish disease heritage.

Simulation analysis suggests that the available family material would be sufficient to reveal the defective gene locus in linkage analysis. Furthermore, it is very probable in a genetic isolate that the increased frequency of some rare disease can be explained by the enrichment of a certain disease-causing allele originating from one common ancestor (founder). Consequently, if a marker is close enough to the disease gene, no recombinations, or only a small number, have occurred between the two loci in the progeny of the founder. In such cases, most of the disease carriers should have the same marker allele in the chromosome containing the disease allele; the two loci are in linkage disequilibrium (23). Thus, in the Finnish population, linkage disequilibrium extending relatively far from the disease locus may be expected, which dramatically increases the informativeness of linkage analyses $(24,25)$.

The advantage of linkage disequilibrium in linkage analysis is 2-fold: 1) not only can recombinations directly deducible in the families under analysis be included, but so can those occurring in their ancestors; 2) families with a single affected child, relatively uninformative in normal recombinational mapping, yield virtually the same information as those with multiple affected children. The ability to extend recombinational mapping to a larger number of families is particularly important in rare recessive disorders such as the IOSCA syndrome.

Our results show that, in addition to the specific clinical features of the IOSCA syndrome, this disease most likely also represents a genetically distinct ataxia syndrome. The random mapping procedure, aiming to assign the location of the gene for the disease, is in progress. Characterization of the IOSCA gene defect is necessary for the development of a clinical diagnosis and genetic counseling of families with an affected child. Eventually, the discovery of the molecular pathogenesis of the IOSCA syndrome will offer new understanding of the molecules essential for the normal function of the CNS.

Acknowledgments. The authors thank Dr. Andrew Lightfoot for valuable advice on the English language when this article was being written.

\section{REFERENCES}

1. Harding AE 1983 Classification of the hereditary ataxias and paraplegias. Lancet 5:1151-1155

2. Koskinen T, Santavuori P, Sainio K, Kallio A-K, Pihko H 1994 Infantile onset spinocerebellar ataxia with sensory neuropathy: a new inherited disease. J Neurol Sci 121:50-56

3. Koskinen T, Sainio K, Rapola J, Pihko H, Paetau A 1994 Sensory neuropathy in infantile onset spinocerebellar ataxia (IOSCA). Muscle Nerve 17:509-515

4. Cocozza S, Antonelli A, Campanella G, Cavalcanti F, De Michele G, Di Donato S, Filla A, Monticelli A, Pianese L, Piccinelli A, Porcellini A, Redolf E, Varrone S, Pandolfo M 1993 Evidence of a genetic marker associated with early onset in Friedreich's ataxia. J Neurol 240:254-256

5. Hanauer A, Chery M, Fujita R, Driesel AJ, Gilgenkrantz S, Mandel JL 1990 The Friedreich ataxia gene is assigned to chromosome $9 q 13-q 21$ by mapping of tightly linked markers and shows linkage disequilibrium with D9S15. Am J Hum Genet 46:133-137

6. Pandolfo M, Sirugo G, Antonelli A, Weitnauer L, Ferretti L, Leone M, Dones I, Cerino A, Fujita R, Hanauer A, Mandel J-L, Di Donato S 1990 Friedreich ataxia in Italian families: genetic homogeneity and linkage disequilibrium with the marker loci D9S5 and D9S15. Am J Hum Genet 47:228-235

7. Ben Hamida C, Doerflinger N, Belal S, Linder C, Reutenauer L, Dib C, Gyapay G, Vignal A, Le Paslier D, Cohen D, Pandolfo M, Mokini V, Novelli G, Hentati F, Ben Hamida M, Mandel J-L, Koenig M 1993 Localization of Friedreich ataxia phenotype with selective vitamin E deficiency to chromosome $8 \mathrm{q}$ by homozygosity mapping. Nature Genet 5:195-200

8. Gatti RA, Berkel I, Boder E, Braedt G, Charmley P, Concannon P, Ersoy F, Foround T, Jaspers NGJ, Lange K, Lathrop GM, Leppert M, Nakamura Y, O'Connell P, Paterson M, Salser W, Sanal O, Silver J, Sparkes RS, Susi E, Weeks DE, Wei S, White R, Yoder F 1988 Localization of an ataxiatelangiectasia gene to chromosome 11q 22:23. Nature 336:577-580

9. Ranum L, Duvick L, Rich S, Schut L, Litt M, Orr H 1991 Localization of the autosomal dominant HLA-linked spinocerebellar ataxia (SCA1) locus, in two kindreds, within an 8-cM subregion of chromosome 6p. Am J Hum Genet 49:31-41

10. Jodice C, Frontali M, Persichetti F, Novelletto A, Pandolfo M, Spadaro M, Giunti P, Schinaia G, Lulli P, Malaspina P, Plasmati R, Tola R, Antonelli A, Di Donato S, Morocutti C, Weissenbach J, M.Cann H, Terrenato L 1993 The 
gene for spinal cerebellar ataxia 1 (SCA1) is flanked by two closely linked highly polymorphic microsatellite loci. Hum Mol Genet 2:1383-1387

11. Gispert S, Twells R, Orozco G, Brice A, Weber J, Heredero L, Scheufler K, Riley B, Allotey R, Nothers C, Hillermann R, Lunkes A, Khati C, Stevanin $G$, Hernandez A, Magarino C, Klockgether T, Durr A, Chneiweiss $H$, Enczmann J, Farrall M, Beckmann J, Mullan M, Wernet P, Agid Y, Freund H-J, Williamson R, Auburger G, Chamberlain S 1993 Chromosomal assignment of the second locus for autosomal dominant cerebellar ataxia (SCA2) to chromosome 12q 23:24.1. Nature Genet 4:295-299

12. Hazan J, Lamy C, Melki J, Munnich A, de Recondo J, Weissenbach J 1993 Autosomal dominant familial spatic paraplegia is genetically heterogeneous and one locus maps to chromosome 14q. Nature Genet 5:163-167

13. Vandenplas S, Wiid I, Grobler-Rabie A, Brebner K, Ricketts M, Wallis G, Bester A, Boyd C, Mathew C 1984 Blot hybridization analysis of genomic DNA. J Med Genet 21:164-172

14. Mullis KB, Faloona FA 1987 Specific synthesis of DNA in vitro via polymerase-catalyzed chain reaction. Methods Enzymol 155:335-350

15. Weissenbach J, Gyapay G, Dib C, Vignal A, Morissette J, Millasseau P, Vaysseix G, Lathrop M 1992 A second-generation linkage map of the human genome. Nature 359:794-801

16. NIH/CEPH Collaborative Mapping Group 1992 A comprehensive genetic linkage map of the human genome. Science 258:67-86

17. Murray J, Duyk G, Sheffield V, Weber J, Buetow K, Weir R, Newkirk N 1993 Cooperative Human Linkage Center Report 1, University of lowa
18. Ott $\mathrm{J} 1989$ Computer-simulation methods in human linkage analysis. Proc Nat Acad Sci USA 86:4175-4178

19. Weeks DE, Ott J, Lathrop GM 1990 A general simulation program for linkage analysis. Am J Hum Genet 47(suppl):A204(abstr)

20. Lathrop GM, Lalouel JM, Julier C, Ott J 1984 Strategies for multilocus linkage analysis in humans. Proc Natl Acad Sci USA 81:3443-3446

21. Hästbacka J, Kaitila I, Sistonen P, de la Chapelle A 1990 Diastrophic dysplasia gene maps to the distal long arm of chromosome 5. Proc Natl Acad Sci USA 87:8056-8059

22. Järvelä I, Schleutker J, Haataja L, Santavuori P, Puhakka L, Manninen T, Palotie A, Sandkuijl LA, Renlund M, White R, Aula P, Peltonen L 1991 Infantile form of neuronal ceroid lipofuscinosis (CLN1) maps to the short arm of chromosome 1. Genomics 9:170-173

23. Hästbacka J, de la Chapelle A, Kaitila I, Sistonen P, Weaver A, Lander E 1992 Linkage disequilibrium mapping in isolated founder populations: diastrophic dysplasia in Finland. Nature Genet 2:204-211

24. Kestilä M, Männikkö M, Holmberg C, Gyapay G, Weissenbach J, Savolainen E-R, Peltonen L, Tryggvason K 1994 Congenital nephrotic syndrome of the Finnish type maps to the long arm of chromosome 19. Am J Hum Genet 54:757-764

25. Hellsten E, Vesa J, Speer MC, Mäkelä TP, Järvelä I, Alitalo K, Ott J, Peltonen L 1993 Refined assignment of the infantile neuronal ceroid lipofuscinosis (INCL, CLN1) locus at 1p32: incorporation of linkage disequilibrium in multipoint analysis. Genomics 16:720-725

\section{Announcement}

Call for Abstracts

The American Pediatric Society and The Society for Pediatric Research announce the abstract deadline for the 1995 Annual Meeting (May 8-11, 1995, San Diego Convention Center) has been set as January 3, 1995.

For further information, contact: APS/SPR Association Headquarters, 141 Northwest Point Blvd., P.O. Box 675, Elk Grove Village, IL 60009-0675, (708) 427-0205, Fax: (708) 427-1305. 